Sánchez, Paola, Política monetaria del BCE y consecuencias en la Unión Monetaria Europea

\title{
Política Monetaria del BCE y CONSECUENCIAS EN LA Unión MONETARIA EUROPEA.
}

\section{ECB Monetary Policy and consequences in the EuRopean MONETARY UNION.}

\author{
PAOLA SANCHEZ \\ Universidad Complutense de Madrid \\ paola.s.fuentes@gmail.com
}

Fecha de recepción: septiembre de 2014 Fecha de aceptación: marzo de 2015

\begin{abstract}
RESUMEN
La crisis de deuda que atraviesa la Unión Europea ha cuestionado el diseño institucional del Sistema Monetario Europeo (SME). Uno de los autores alemanes más influyentes, Werner Sinn, argumentó en el año 2011 que el Banco Central Europeo (BCE) estaba financiando los déficits por cuenta corriente de los países de la periferia y que esto se estaba reflejando en un incremento de los desequilibrios en el sistema de pagos TARGET2, lo cual suponía un riesgo importante para los países del centro de Europa. Este trabajo pretende demostrar que estos desequilibrios surgen como consecuencia de la parálisis del mercado interbancario y de la actuación del BCE a la hora de evitar el colapso del sistema financiero. Estos desequilibrios no suponen un problema en sí mismos, sino que son el reflejo de decisiones de política económica adoptadas por el BCE frente a la crisis. La argumentación de Sinn esconde una defensa de las políticas de austeridad y la necesidad de mejorar la competitividad de los países del sur de Europa para reducir las posiciones deudoras de estos países frente al Euro-sistema.
\end{abstract}

Palabras clave: TARGET2, BCE, Política Monetaria, Euro-sistema, mercado interbancario.

\section{ABSTRACT}

The European Union debt crisis has questioned the institutional design of the European Monetary System (EMS). In 2011, one of the most influential authors, Werner Sinn, argued that the European Central Bank (ECB) was financing the current account deficits in the periphery countries and for this reason, the TARGET2 imbalances were dangerously increasing the risk in core countries. This paper considers that the TARGET2 imbalances have their roots in the interbank market paralysis and in the ECB role in the crisis, avoiding the financial system collapse. However, these imbalances are not a single problem but to reflect the political economy decisions. Sinn's arguments hide a defence to austerity policies and the need to improve the competitiveness in the Southern countries and therefore the liabilities vis-à-vis the Euro-system. 
Sánchez, Paola, Política monetaria del BCE y consecuencias en la Unión Monetaria Europea

Key words: TARGET2, ECB, Monetary Policy, Euro-system, interbank market.

JEL: E52, E58, E41.

\section{INTRODUCCIÓN}

El sistema TARGET2 (Trans-European Automated Real-Time Gross settlement Express Transfer System) es un sistema de pagos interbancarios para el procesamiento en tiempo real de las transferencias monetarias transfronterizas en toda la Unión Europea. Las transacciones de pago se liquidan una por una en una base continua en dinero del Banco Central Europeo de forma inmediata. Se asienta principalmente en operaciones de política monetaria y las operaciones del mercado monetario ${ }^{1}$. Aunque hay que señalar que existen otros sistemas de pagos en la Unión Europea como el sistema EURO1, éstos no llegan a alcanzar ni un 10\% del tamaño del TARGET2.

Según el esquema descentralizado de TARGET2, los participantes en el sistema que, por regla general, han de ser entidades de crédito $^{2}$, siguen manteniendo sus cuentas en los bancos centrales nacionales. Las operaciones domésticas se siguen liquidando en el banco central correspondiente. En cuanto a los pagos transfronterizos entre países de la UE, se canalizan a través de los bancos centrales correspondientes a la entidad pagadora y a la entidad receptora del pago. Para ello, todos los bancos centrales están conectados entre sí, y con el Banco Central Europeo, formando lo que se ha denominado la red o mecanismo de interlinking.

El interés por conocer el funcionamiento de dicho sistema, ha cobrado relevancia en la crisis de deuda europea. A partir del año 2007, la posición en el sistema TARGET2 de los Bancos Centrales Nacionales europeos con respecto al Banco Central Europeo (BCE) se ha modificado, como veremos, a partir de la paralización del mercado interbancario.

Economistas como Werner Sinn y Wollmershäuser (2011), han llegado a plantear que el sistema TARGET2 se ha usado para financiar insostenibles déficit corrientes de países del sur de Europa; así como que Alemania y otros países del norte de Europa se han visto forzados a proveer de créditos a los países del sur, acumulando posiciones acreedoras frente al sistema TARGET y aumentando los riesgos para Alemania en el caso de que se desintegrara la Unión Europea.

El objetivo de este trabajo es demostrar que los desequilibrios en el sistema TARGET2 se intensifican a consecuencia de la parálisis del mercado interbancario tras la crisis financiera del año 2007, y la posterior intervención

\footnotetext{
${ }^{1}$ Este sistema refleja contablemente los movimientos de dinero entre los distintos países que forman parte de la plataforma, y que se deben, en su mayoría, a operaciones de política monetaria (como por ejemplo la inyección de liquidez al sistema) o bien a operaciones de mercado abierto y facilidades permanentes, que son las principales herramientas de las que dispone el BCE para la creación de masa monetaria.

${ }^{2}$ Los participantes en el TARGET2 son los bancos centrales de la UE y el BCE, así como entidades de crédito establecidas en el Espacio Económico Europeo (EEE). También se permite la participación de entidades de crédito establecidas fuera del EEE, siempre que actúen a través de una sucursal que sí esté establecida dentro del EEE.
} 
Sánchez, Paola, Política monetaria del BCE y consecuencias en la Unión Monetaria Europea

del BCE inyectando liquidez en el sistema. Los préstamos proporcionados por el BCE a los bancos de los países con mayores problemas de liquidez aumentaron los desequilibrios reflejados en el TARGET2, fruto del propio funcionamiento del sistema de pagos. Para ello se analizará el funcionamiento del sistema TARGET2 antes y después de la crisis, centrándonos principalmente en comparaciones entre España y Alemania (aunque a veces se incluyen otros países periféricos); para ver cuáles han sido las causas de los desequilibrios y la política que se ha llevado a cabo desde el BCE para estabilizar la situación.

\section{FUNDAMENTOS TEÓRICOS DE LA INVESTIGACIÓN}

\subsection{Contexto}

Con la creación de la Unión Monetaria Europea (UEM), los países miembros que la conforman pasaron a compartir una política monetaria única, es decir, el ingreso en una Unión Monetaria supone para todos los países participantes la pérdida de dos de los instrumentos de política económica con los que cuentan los estados para aplicar políticas macroeconómicas: el tipo de cambio y el tipo de interés.

En principio, esto no tendría por qué suponer un problema si el comportamiento de los países fuese homogéneo, lo cual es algo que nunca ocurre. La idea central del marco de aplicación de las políticas macroeconómicas de la Zona Euro es que éstas deben orientarse principalmente a garantizar la estabilidad de precios y la estabilidad de las finanzas públicas. Para ello, se creó un banco central totalmente independiente del poder político, y en definitiva, se estableció un marco institucional que redujo al mínimo la gestión de la economía a través de políticas macroeconómicas, bajo la premisa de que son sistemas que tienden a autorregularse siempre que se asegure el funcionamiento flexible del mercado y un clima de estabilidad macroeconómica (Álvarez et al., 2013).

Sin embargo, con la llegada de la crisis, se hizo más evidente el comportamiento "heterogéneo" de los diferentes países que ya venía mostrándose desde la creación de la UEM (diferentes tasas de crecimiento, inflación, saldo por cuenta corriente...). Se muestran así dos bloques claramente diferenciados: los que han registrado superávits por cuenta corriente, y aquellos que han presentado durante todo el período déficits crecientes. La contrapartida a cualquier déficit por cuenta corriente es la necesidad de financiación del conjunto de la economía, lo que implica que el país se está endeudando o reduciendo sus activos con el exterior y que se están acumulando posiciones deudoras. En el caso contrario, los países con superávit presentan un exceso de ahorro que se canaliza de alguna forma hacia el exterior en forma de adquisición neta de activos.

Es a partir del año 2007, cuando estos desequilibrios se hacen más evidentes y surge el debate sobre la evolución de los balances de los bancos centrales en el sistema TARGET2, ya que en este sistema se realizan las anotaciones contables de los movimientos de dinero entre las distintas entidades de los 
Sánchez, Paola, Política monetaria del BCE y consecuencias en la Unión Monetaria Europea

países de la eurozona. El debate se centra en discutir cuáles son las causas de los crecientes desequilibrios y cuáles son los posibles riesgos que se derivan de éstos.

\subsection{El inicio del debate}

La discusión gira en torno a dos economistas principalmente, que han generado dos visiones diferentes acerca de la situación. Estos son HansWerner Sinn y Paul de Grauwe. La primera de ellas, representada por Sinn, defiende la hipótesis de que los desequilibrios existentes en el sistema TARGET2 son reflejo de una financiación por parte del BCE hacia los países periféricos, lo cual supone un riesgo cada vez mayor para los contribuyentes alemanes en caso de ruptura del euro. La segunda, encabezada por De Grauwe rebate esta idea señalando que no existe dicho riesgo y califica de infundados los argumentos de Sinn.

En junio de 2011, Hans-Werner Sinn, profesor de economía y finanzas públicas de la universidad de Munich y presidente del Ifo Institute for Economic Research, publicó el artículo "The ECB's stealth bailout" ("El rescate secreto del BCE"), en el que cuestionaba el funcionamiento del sistema TARGET2 y el riesgo que suponían los desequilibrios en los balances TARGET para la Zona Euro. Al año siguiente, junto con Wollmershäuser, publica el documento "Target loans, current account balances and capital flows" en el cual argumenta las ideas señaladas en su primer artículo y responde a las primeras críticas recibidas.

La argumentación de este autor consta de dos partes. En la primera de ellas argumenta que el sistema TARGET2 es un sistema remotamente escondido en una esquina del BCE, cuyo balance muestra la financiación por parte del BCE de los grandes déficits de balanza de pagos de la periferia a expensas de los países del centro de la Eurozona. Esto ha convertido a los bancos centrales del centro en deudores netos ${ }^{3}$ de sistemas bancarios periféricos (Sinn, 2012). Las instituciones de la periferia que han sido financiadas solamente se han encargado de pedir prestado y de desprestigiar a la moneda europea. Además, acusa a los países de la periferia de haberse aprovechado del funcionamiento del sistema, puesto que estos países han recibido financiación a través del BCE y han sido ayudados en la misma forma que lo hubieran hecho las líneas de rescate. La diferencia es que no han tenido que asumir las condiciones establecidas en las líneas de rescate. Es decir, los países de la periferia han disfrutado de un "rescate oculto" que ha evitado la aplicación de los programas de rescate oficiales.

En la segunda parte, señala el riesgo que supone para Alemania la permanencia de estos desequilibrios en el balance del Euro-sistema. El colapso del sistema llevaría a los contribuyentes alemanes a pagar parte de la deuda de los países de la periferia, ya que cada uno de los bancos centrales

\footnotetext{
${ }^{3}$ Aunque esta terminología pueda dar lugar a confusión, el hecho de que un país se califique de ser deudor neto, implica que la diferencia entre la financiación concedida (activo) y la recibida (pasivo) es positiva. En caso contrario sería acreedor neto.
} 
Sánchez, Paola, Política monetaria del BCE y consecuencias en la Unión Monetaria Europea

nacionales responde ante el BCE en un porcentaje predeterminado. Además, el riesgo sería elevado dado el tamaño de los desequilibrios. El hecho de que el BCE esté financiando los déficits por cuenta corriente con dinero adicional supone un riesgo mayor para los países superavitarios que son los que están financiando a los países de la periferia. Ante las críticas que señalan que los contribuyentes alemanes no corren ningún riesgo responde: "esta afirmación es tan cierta como decir que el accidente de un jet Jumbo no implica ningún riesgo más allá que la caída del avión" (Sinn, 2012; 473).

En cuanto a las soluciones al problema, afirma que si el BCE no hubiese tenido que hacer de "guía" a los países de la periferia, forzándolos a realizar recortes presupuestarios, el mercado hubiera equilibrado la cuenta corriente y los movimientos de capital. Defiende que en caso de regulación del BCE, la política debe ir orientada a facilitar los movimientos de capital si su objetivo es compensar los balances, ya que si continúa interviniendo "rescatando a los países" seguirán existiendo déficits corrientes y se mantendrán los problemas.

Una mayor contracción de la economía, con una devaluación interna, tendría como resultado la estimulación de las exportaciones, la reducción de las importaciones y la caída de los déficits por cuenta corriente. Para Sinn el BCE se está encargando no solo de calmar el dolor, sino también de socavar la función distributiva del mercado, intentando mejorar la situación de la periferia que presenta necesidades financieras incesantes y donde los niveles de deuda aumentan hasta el punto que pueden convertirse en insostenibles.

\subsection{La respuesta de De Grauwe y la visión heterodoxa de Whelan}

Paul De Grauwe (2012), como representante de la segunda corriente, responde a Sinn en su artículo "What Germany should fear most is its own fear". Para este autor, los argumentos de Sinn no están fundamentados. Los desequilibrios reflejados en el sistema TARGET no necesariamente tienen que financiar déficits por cuenta corriente por dos motivos: primero porque el perfil temporal de las cuentas corrientes de los países es diferente al del TARGET2 ${ }^{4}$; y segundo, la volatilidad de los desequilibrios en el TARGET2 es mucho mayor que en las balanzas comerciales, lo que lleva a pensar que los movimientos a corto plazo en el sistema TARGET2 están dominados por movimientos especulativos.

\section{Afirma que:}

Mientras que las posiciones por cuenta corriente pueden haber afectado a los balances del TARGET después de 2008, la mayoría de éstos tienen otro origen. Identificamos que se trata de movimientos especulativos provocados por el miedo y el pánico (De Grauwe, 2012; 7).

Cuando el miedo y el pánico afecta a los mercados de bonos soberanos (como ocurre desde 2008); los tenedores de bonos venden los bonos de los países en los que desconfían y compran bonos considerados seguros. Esto tiende a aumentar los rendimientos de los bonos de los países menos seguros y baja el

\footnotetext{
${ }^{4}$ La balanza de pagos se muestra mensual, trimestral o anualmente; mientras que los movimientos en el sistema TARGET2 se hacen día a día.
} 
Sánchez, Paola, Política monetaria del BCE y consecuencias en la Unión Monetaria Europea

rendimiento de los seguros. Así, los movimientos pueden ser utilizados como indicadores de los movimientos de miedo y pánico, y son aquellos que se muestran en los desequilibrios del TARGET2.

El modelo econométrico presentado por De Grauwe (ib.) sugiere comprobar si los saldos TARGET2 están relacionados con los flujos de capital especulativo. Para ello, relaciona los desequilibrios TARGET2 con los rendimientos de los bonos del gobierno, que actúan como indicadores del "estrés" especulativo. Se espera que los países que experimentan un aumento de los rendimientos (como Irlanda, Grecia, Portugal, España e Italia) también acumulen pasivos en el TARGET2; mientras que países con una disminución de estos rendimientos acumulen activos en el TARGET2 (Finlandia, Alemania, Países Bajos). Además de esto, propone controlar otras variables como las cuentas corrientes al realizar las regresiones del modelo.

Como resultado se observa que la relación entre los desequilibrios en el TARGET y los rendimientos de los bonos de deuda pública, es significativa solamente a partir del año 2008, es decir, las oleadas especulativas en los rendimientos de los bonos están asociados a un aumento de los pasivos en el TARGET de los países que se encuentran "bajo presión"; mientras que países que ven disminuido el rendimiento de sus bonos del gobierno, acumulan activos. Se observa además que la cuenta corriente no tiene una correlación significativa con los saldos en el sistema TARGET. Solamente existe relación con la tasa de crecimiento del país, es decir, un aumento de la tasa de crecimiento tiende a estar asociada con un aumento de la posición acreedora en el sistema TARGET.

Con este argumento, De Grauwe intenta probar la idea de Sinn sobre la financiación de los déficits por cuenta corriente, mostrando que los desequilibrios no van asociados a estos déficits sino a los movimientos de capital hacia el centro de Europa que son resultado de oleadas de pánico especulativo.

Como se ha señalado con anterioridad, Sinn (2012) apoya la idea de que los déficits de la periferia están siendo financiados gracias a Alemania y otros países del centro; lo cual implica un riesgo cada vez mayor para estos países en caso de ruptura del euro si continúan aumentando estos desequilibrios. De Grauwe se encarga de refutar esta segunda idea.

Antes de ello aclara que de los cuatro países que presentan posiciones acreedoras (Luxemburgo, Finlandia, Holanda y Alemania), Alemania es el que tiene un menor porcentaje de activos y pasivos en TARGET2 con respecto al PIB (24\%). Por tanto, en caso de ruptura del euro, o de impago por parte de los países "financiados" Alemania sería la menos perjudicada.

En la primera parte, De Grauwe (2012) argumenta que si Alemania se encuentra en la posición de acreedor frente al resto de la zona euro, esto es porque Alemania ha acumulado superávits por cuenta corriente. Esto lleva a dos ideas. Primero, es cierto que acumular grandes cantidades de deuda extranjera puede suponer un riesgo que se materializará cuando los países 
Sánchez, Paola, Política monetaria del BCE y consecuencias en la Unión Monetaria Europea

deudores no puedan pagar sus deudas; y segundo, este riesgo no se mide por la posición acreedora alemana. Es decir, el hecho de que aumentasen los desequilibrios del TARGET2 a partir del año 2010 de forma espectacular, no cambia el riesgo para Alemania. Sino que, como se argumentaba anteriormente, estas posiciones son fruto de movimientos especulativos y lo único que cambia es la composición de los activos y pasivos del TARGET.

Para aclarar esta última idea propone el siguiente ejemplo:

Supongamos que los tenedores de euros en España temerosos de una salida de España, deciden trasladar sus depósitos en euros a un banco alemán. El resultado del flujo especulativo es doble. En primer lugar, esto pone en marcha el sistema de pagos TARGET2. La transferencia de depósitos desde España a Alemania tiene el efecto de que el Banco de España (que hace la transferencia) incrementa sus pasivos en el TARGET2 con respecto al Euro-sistema, mientras que el Bundesbank (que recibe la transferencia) incrementa sus activos frente al Euro-sistema. En segundo lugar, el banco alemán (que adquiere una posición de reserva en el Bundesbank) tiene una obligación frente a un residente español (un depósito). Como resultado, los activos exteriores netos de Alemania no se ven afectados por este flujo especulativo. Una mayor posición acreedora de Alemania se ve compensada con un pasivo del banco alemán; por lo que el incremento de los activos no debe interpretarse como un incremento de los activos extranjeros de Alemania, y por tanto como un aumento de la exposición al riesgo (De Grauwe, 2012; 15).

El hecho de que se paralizara el mercado interbancario, supuso para el BCE la obligación de intervenir inyectando liquidez al sistema para evitar el colapso. El papel del BCE fue canalizar la liquidez procedente de países como Alemania, hacia los países del sur; lo cual implica que la posición de Alemania en el TARGET no puede ser interpretada como un aumento del riesgo para dicho país, sino como un signo de que Alemania sigue acumulando superávits por cuenta corriente.

En la segunda parte de la argumentación, señala que la idea de que existe un riesgo para los contribuyentes alemanes en caso de ruptura del euro, es falsa y se debe a un error de comprensión del funcionamiento del BCE. El principal error es creer que el valor de la base monetaria (los pasivos del banco central) viene determinado por el valor de los activos en poder del banco central. De ahí que se afirme que si la zona euro llega a derrumbarse el valor de los activos del Bundesbank caería y conllevaría una pérdida para el contribuyente alemán. Esto, para De Grauwe, es una conclusión errónea:

El valor de la base monetaria, está determinado exclusivamente por su poder adquisitivo en términos de bienes y servicios. Este valor es independiente del valor de los activos en poder del banco central. De hecho, en el sistema de dinero fiduciario en el que vivimos, el banco central podría literalmente destruir los activos sin ningún efecto sobre el valor de la base monetaria (De Grauwe, 2012; 17).

Por otro lado, suponiendo que el euro quebrase, los bancos centrales tendrían que convertir los euros a la nueva moneda nacional. Digamos que Alemania anuncia convertir los euros en marcos a tipo de cambio de 1 a 2 (1 euro por 2 marcos alemanes, como al inicio de la implantación del euro). El riesgo se podría dar cuando muchos no residentes tratasen de convertir sus euros en Alemania para beneficiarse de un tipo de cambio más atractivo que el de sus propios países. Esto supondría que el Bundesbank se vería obligado a convertir tantos euros en marcos que no se podría mantener la estabilidad de 
Sánchez, Paola, Política monetaria del BCE y consecuencias en la Unión Monetaria Europea

precios y supondrían pérdidas para los residentes alemanes. Sin embargo, el Bundesbank podría intervenir limitando la conversión para evitar problemas de inflación.

Además, los países periféricos serían castigados porque sus ciudadanos asumirían una pérdida a consecuencia de la depreciación de la moneda. El contribuyente alemán, no tendría por qué compartir esta pérdida. Los bancos centrales de la periferia aplicarían un tipo de cambio devaluado, por lo que tendrían que devolver una cantidad mayor de deuda (la tendrían que pagar en marcos) y esto conllevaría grandes pérdidas a sus titulares. La restricción de Alemania a convertir los euros en marcos, aseguraría que las pérdidas que ocurrirían como resultado de una excesiva emisión de deuda en los países periféricos fuese asumida por los residentes de estos países, y no por los contribuyentes alemanes. Dicho de otra forma, esta restricción es el equivalente a expulsar los pasivos devaluados del balance del Bundesbank para devolverlos a los balances de los países deudores (De Grauwe, 2012). En definitiva, el problema para De Grauwe es que la falta de entendimiento acerca del funcionamiento del sistema monetario, ha creado un ambiente donde emergen miedos irracionales, y el miedo se ha convertido en una fuerza política que hace más difícil a los gobiernos encontrar soluciones a la crisis.

Por su parte, Karl Whelan (2013) discute la argumentación de Sinn desde una perspectiva poskeynesiana. Señala que la visión de Sinn sobre el "rescate oculto" a los países de la periferia es inexacta. Su argumentación sirve incluso a De Grauwe para afirmar, como se ha explicado anteriormente, que una ruptura del euro podría llegar a suponer ingresos ordinarios netos más altos para Alemania. A pesar de esto, se enfrentaría a otros problemas relacionados con su orientación exportadora y los contribuyentes tendrían que pagar un alto precio para seguir manteniendo la moneda y la solvencia del sistema bancario.

Además, según este mismo autor, muchas de las críticas a los saldos mostrados en el TARGET2 se convierten en críticas a la forma en la que se ha aplicado la política monetaria en la zona euro, ya que la actuación del BCE ha consistido en inyectar liquidez a instituciones de crédito que presentaban problema de liquidez, sin distinción de la localización de éstas y haciendo caso omiso a las presiones por parte de ciertos países para que abandonase esta política o para que restringiese la utilización del sistema de pagos a ciertos países. Esto último incluso podría ser incompatible con la continuación del euro como moneda común porque estos desequilibrios son consecuencia de la libre circulación de capital y para controlar los saldos, habría que regular los movimientos de dinero y en consecuencia, no se estarían cumpliendo los acuerdos adoptados con la creación del euro. Añade además, que este debate ha surgido a consecuencia de la renuncia de los bancos centrales a hablar sobre los problemas que realmente afectarían a los ciudadanos en caso de ruptura del euro y ha ocupado un lugar central ocultando cuestiones importantes que sí que tendrían una repercusión social.

A pesar de la limitada literatura existente sobre este tema dada su reciente aparición en el debate económico, diversos autores muestran su visión sobre los problemas que pueden acarrear estos desequilibrios. Sin embargo, se 
Sánchez, Paola, Política monetaria del BCE y consecuencias en la Unión Monetaria Europea

observa claramente una línea divisoria entre unos y otros autores; por un lado, aquellos que apoyan las ideas de Sinn, (normalmente autores alemanes), y por otro, autores que apoyan a De Grauwe o que amplían su análisis desde una corriente más crítica.

Este artículo se centrará en explicar los desequilibrios existentes en el sistema TARGET2 partiendo de esta última perspectiva y desde una visión heterodoxa, comprobando que éstos no son un problema en sí mismos, sino que son el reflejo de otros problemas existentes en la Unión Europea, entre los que se encuentra la falta de confianza existente en los países periféricos. Esto ha generado movimientos de capital hacia el centro y grandes problemas de liquidez en los países de la periferia, que se han visto compensados con créditos del BCE reflejados en los movimientos en el TARGET2 y que han evitado una crisis financiera mayor.

\subsection{El porqué de la investigación}

En períodos de turbulencia o de mal funcionamiento de la economía, cobra especial interés la forma en la que se toman las decisiones de política económica. El debate iniciado por Sinn sobre los desequilibrios en el sistema TARGET se ha convertido en un tema relevante dentro de las discusiones sobre la política monetaria llevada a cabo por el BCE durante la crisis.

Es por ello que se intentará mostrar cuáles han sido los orígenes de los desequilibrios partiendo de la parálisis del mercado interbancario con el inicio de la crisis en el año 2007, y ver qué se ha ido mostrando en los balances del sistema TARGET2. Posteriormente veremos que estos desequilibrios no son un problema en sí mismos, sino que son el reflejo de problemas de índole política y que nada tienen que ver con el mal o buen funcionamiento del sistema TARGET durante la crisis.

Para ello se mostrarán las posiciones de los balances que presenta cada uno de los países con respecto al Euro-sistema, relacionando su posición con los déficits o superávits por cuenta corriente, las decisiones de política económica tomadas desde el BCE y los problemas existentes en el mercado interbancario; todo ello con el objetivo de contrastar la hipótesis de Sinn.

Se plantean, por tanto, dos hipótesis diferenciadas. La primera de ellas señala que el origen de los desequilibrios surgidos en el sistema TARGET2 no tienen su origen en la financiación del BCE de los déficits por cuenta corriente de los países periféricos; y la segunda, que el hecho de señalar los déficits por cuenta corriente como origen de los desequilibrios e intentar solucionar éstos a través de la devaluación interna de los países periféricos da un enfoque al debate que muestra una defensa de las políticas de austeridad. 
Sánchez, Paola, Política monetaria del BCE y consecuencias en la Unión Monetaria Europea

\section{DESARROLLO DE LA INVESTIGACIÓN. ANÁLISIS DEL FUNCIONAMIENTO DEL SISTEMA TARGET2 Y SU RELACIÓN CON EL MERCADO INTERBANCARIO DE LA UEM}

\subsection{La evolución del sistema TARGET desde su creación hasta la crisis de 2008}

El volumen de dinero que se mueve en los mercados financieros, ha influido en su desarrollo y en el interés por conocer el funcionamiento de los sistemas de pagos, infraestructuras necesarias para su funcionamiento. En Europa, con la llegada de la moneda única, se aceleró el proceso de cambio de los sistemas de pago y se llevó a cabo una adaptación y consolidación de las infraestructuras para poder adaptarlas al funcionamiento de la Unión Monetaria Europea.

El sistema TARGET se constituye en el año 1995 bajo los principios de libre mercado y descentralización, y su creación viene influida por el proceso de integración europeo y el mal funcionamiento de los sistemas de pagos existentes en la Unión Europea en ese momento. Hasta 2008, este sistema respondió a una estructura descentralizada; pero entre los años 2003 y 2007 el Euro-sistema diseñó y probó el nuevo sistema TARGET2 con el objetivo de garantizar una mayor eficiencia de los pagos, permitir una fácil integración y mejorar el servicio a los usuarios (Alonso y Conesa, 2011). Al cumplir estos objetivos, TARGET2 contribuiría a la integración y la estabilidad del mercado monetario de la zona euro. Este sistema se describe como una plataforma a través de la cual se liquidan las operaciones de política monetaria y se realizan pagos entre entidades bancarias de los diferentes países de la zona euro en dinero del banco central.

La crisis financiera que viene produciéndose desde 2008, no ha afectado al funcionamiento del TARGET2 como infraestructura ya que muestra las anotaciones contables resultantes de movimientos de dinero efectuados dentro de la Unión Monetaria. Pese a ello, los efectos de la crisis si se han puesto de manifiesto en los balances de las entidades participantes.

El debate existente se centra en la evolución que han experimentado los balances de los Bancos Centrales dentro del sistema TARGET2 tras el inicio de la crisis. En la cuenta intra-Euro-sistema, los bancos centrales han adoptado una clara posición acreedora 0 deudora que ha ido aumentando progresivamente. Los pagos hacia el exterior provocados por un saldo por cuenta corriente negativo, las inversiones directas en el exterior, o la devolución a inversores extranjeros de inversiones previas, o la centralización de la gestión de la tesorería de las entidades multinacionales, son algunos de los elementos que causan posiciones deudoras con respecto al Banco Central Europeo (BCE) (Alonso y Conesa, 2011). En general, todas aquellas operaciones que supongan un déficit por cuenta corriente o un incremento del activo en el exterior, es decir, que exista una salida de capital mayor a la entrada, causan las posiciones deudoras de los países. 
Sánchez, Paola, Política monetaria del BCE y consecuencias en la Unión Monetaria Europea

\subsection{La parálisis del mercado interbancario}

El mercado interbancario es aquel en que se cruzan operaciones entre entidades de crédito, el banco emisor y, en ocasiones, otras instituciones de carácter financiero. Las instituciones financieras se ceden depósitos a plazos ordinariamente muy cortos, de elevada liquidez y bajo riesgo, directamente o a través de mediadores especializados. La utilidad básica que dio origen al mercado interbancario es la posibilidad de que a él concurran bancos y cajas de ahorros sobrados o faltos de liquidez, con el objetivo de ofrecer o demandar dinero para corregir sus desequilibrios de tesorería.

Cuando las entidades no captan dinero suficiente para satisfacer la demanda de crédito puede recurrir al mercado interbancario para conseguirlo, bien de una entidad bancaria o del BCE. En el lado opuesto se encontraría una entidad con excedente de liquidez y para no mantener el dinero ocioso, recurre al mercado interbancario con el objetivo de prestar el excedente de liquidez y así obtener un rendimiento. Actualmente, en la zona euro, dado su funcionamiento se podría hablar de dos mercados interbancarios. El primero sería aquel que engloba las operaciones entre entidades financieras; mientras que el segundo, sería el mercado interbancario donde actúa el BCE y las entidades financieras de la zona euro, y que es utilizado como un medio de control de la política monetaria europea.

Cuando se quiere controlar o disminuir la inflación, el BCE incrementa el tipo de interés oficial, por lo que los préstamos concedidos entre las entidades se realizarán a un tipo de interés más elevado. En caso contrario, cuando se busca el estímulo a la actividad económica, el BCE bajará los tipos de interés oficiales. En el gráfico 1 se muestra la evolución que han presentado los tipos de interés del mercado interbancario desde el inicio de la crisis.

Gráfico 1. Evolución del tipo de interés en tanto por ciento en el mercado interbancario durante la crisis.

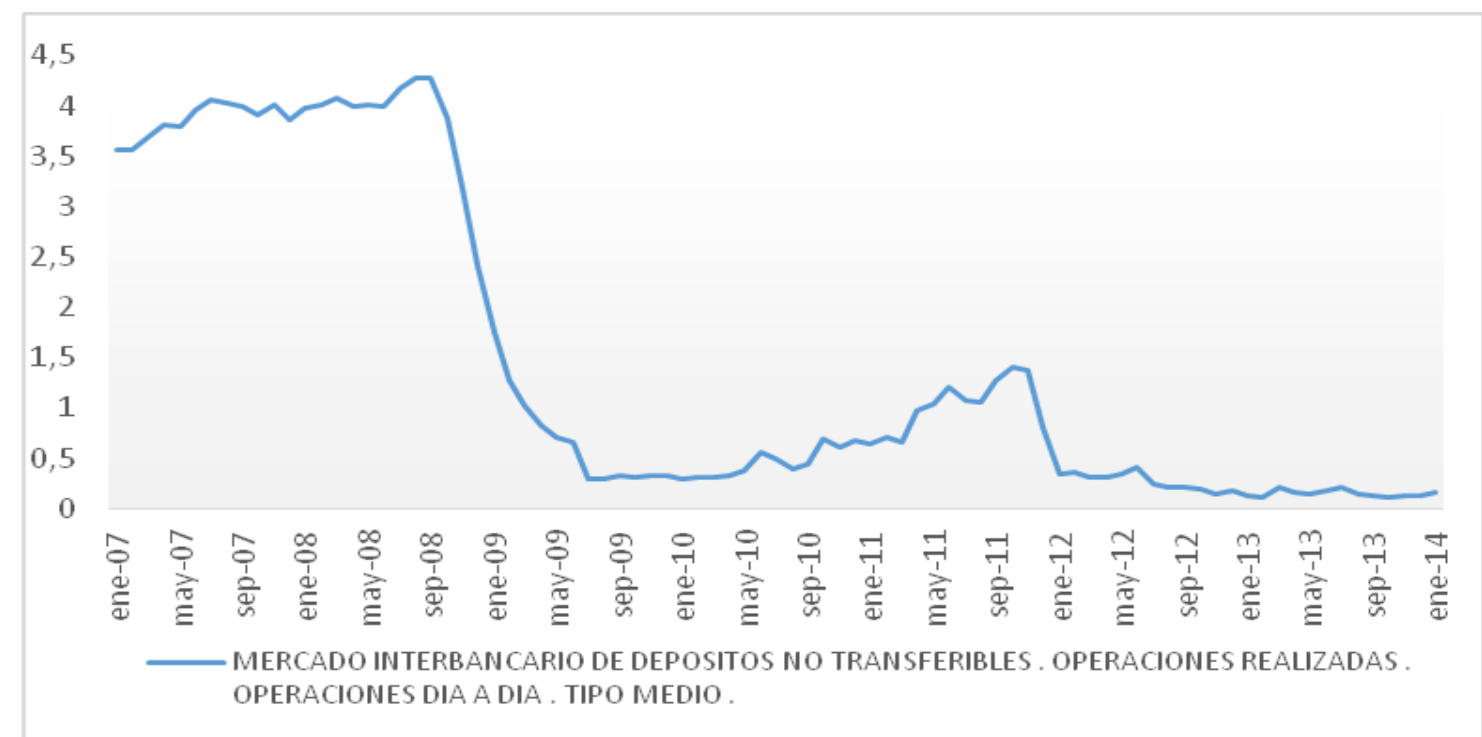

Fuente: Elaboración propia a partir de datos del Banco de España. 
Sánchez, Paola, Política monetaria del BCE y consecuencias en la Unión Monetaria Europea

La caída espectacular observada desde septiembre del año 2008 señala el inicio "oficial" de la crisis. A partir de este año, el BCE llevó a cabo una política monetaria expansiva y situó los tipos de interés por debajo del $1 \%$ manteniendo esta política durante los años posteriores, exceptuando el año 2011 durante el cual el BCE decidió aumentar los tipos de interés hasta el 1,25\%, política muy criticada que posteriormente tuvo que ser corregida volviendo a bajar los tipos de interés. Sin embargo, como se observa en el gráfico 2 , a pesar de que se pudiese observar una ligera recuperación de las negociaciones entre mayo de 2010 y marzo de 2011, esta se vio interrumpida con la subida de los tipos de interés y no se observa una recuperación clara a pesar de los estímulos del BCE.

Tomando datos sobre la media mensual del tamaño de las operaciones en el mercado interbancario a un día en millones de euros desde enero de 2007 hasta septiembre de 2013, la actividad del mercado interbancario por operaciones de depósito alcanzó su valor máximo en el 2007 para caer desde entonces más del $60 \%$. Esta disminución, no se vio compensada por la operativa de financiación con colateral (normalmente operaciones repo ${ }^{5}$ ) puesto que como señala Díez (2013) estas operaciones también disminuyeron.

Según Combis (2013), se pueden establecer diferentes razones para explicar el cambio producido en el mercado interbancario:

- La crisis de deuda soberana propagada en el sistema bancario ha aumentado la aversión al riesgo de las entidades.

- La estructura del unsecured market (mercado no garantizado) ha cambiado promoviendo operaciones a nivel nacional en vez de operaciones intra euro, que han caído significativamente. La traslación del riesgo país al riesgo de crédito ha provocado una disminución importante de la actividad entre entidades de distintos países.

- La menor calidad crediticia de las entidades que han visto rebajado su rating en consonancia con las bajadas de rating del riesgo soberano. Esto ha provocado que las líneas de riesgo asignadas a las entidades españolas quedasen limitadas y la operativa interbancaria muy reducida.

- Otra razón, o tal vez consecuencia de lo anterior, ha sido la preferencia de las entidades por acceder a la facilidad de depósito del BCE dados los bajos tipos de interés y la preocupación o desconfianza creciente sobre la calidad crediticia de otros participantes del mercado. Así el BCE se ha erigido en el gran receptor del excedente de liquidez a través de su facilidad de depósito.

- El resultado de las operaciones de mercado abierto a largo plazo (LTROs) convocadas durante diciembre de 2011 y febrero de 2012 en el Eurosistema, permitieron cubrir ciertas necesidades de financiación de las entidades.

\footnotetext{
${ }^{5}$ Las operaciones de repo son operaciones con pacto de recompra, es decir, una entidad financiera vende un activo con un pacto de recompra a un precio determinado dentro de un tiempo determinado. Se suelen dar con títulos de deuda pública como letras, bonos y obligaciones del estado. El pacto de recompra se realiza a un tipo de interés determinado, por lo que el inversor recibirá su dinero más un beneficio. Se trata de una forma de obtener liquidez a corto plazo para los bancos. También es un instrumento de política monetaria de los bancos centrales.
} 
Sánchez, Paola, Política monetaria del BCE y consecuencias en la Unión Monetaria Europea

Estos factores han provocado una importante disminución de la actividad en el mercado interbancario y consecuentemente esto ha afectado al papel principal de intermediario financiero que se espera de los bancos.

EI BCE tuvo un papel fundamental a la hora de reponer la liquidez inexistente, lo cual se refleja, como analizaremos más adelante en el gráfico 6, en el nivel de préstamos concedidos a las entidades privadas, y en consecuencia en el balance del TARGET2.

\subsection{Cómo funciona el sistema TARGET2 y cómo afectó la parálisis del mercado interbancario a su funcionamiento}

Para entender el funcionamiento dentro del sistema TARGET2, veamos cómo surgen estos saldos con un ejemplo simplificado. Supongamos que una empresa española compra maquinaria por $100 €$ a una empresa alemana. Ambas empresas tienen cuentas bancarias en entidades de sus respectivos países y el pago de la importación de la maquinaria se realiza a través de TARGET2. En la entidad española (A), la cuenta del cliente aparece en su pasivo, por lo que el pago supone una disminución de dicho pasivo en $100 €$. Para abonar a la entidad alemana (B), el banco A utiliza fondos en su cuenta de TARGET2 (abierta en los libros del Banco de España), por lo que el adeudo en dicha cuenta supone una disminución de su activo en $100 €$. En paralelo, la entidad B recibe $100 €$ en su cuenta TARGET2 (abierta en los libros del Bundesbank). Se produce pues un incremento de su activo en $100 €$ por el abono en dicha cuenta y un incremento de su pasivo de $100 €$ al abonar esta cantidad en la cuenta del fabricante de la maquinaria.

La contrapartida de estas operaciones se refleja en la cuenta técnica intra-eurosistema que aparece en el balance de los bancos centrales adheridos a TARGET2 y que recoge los saldos netos acumulados de las operaciones transfronterizas enviadas y recibidas por sus participantes. Así, el Banco de España tendría un saldo deudor de $100 €$ y el Bundesbank un saldo acreedor de $100 €$. Si calculásemos en este momento el balance consolidado del Eurosistema, las cuentas se anularían, por lo que no tendría ningún efecto en la masa monetaria del BCE. Esto refleja que las entidades operan en una unión monetaria.

A final del día, las entidades deben ajustar su liquidez. Si la única operación que se realiza fuera esta transferencia de $100 €$, al final del día, la entidad $A$ desea reponer su liquidez, mientras que $B$ tiene un exceso de liquidez disponible. Si el mercado interbancario europeo funcionara normalmente, parece lógico suponer que el Banco B prestaría su exceso de liquidez al banco A través de una transferencia que podría canalizarse por TARGET2. De este modo, se registraría un pago en sentido contrario al inicial que saldaría las cuentas intra-Euro-sistema de los respectivos bancos centrales.

Esto no genera ningún desequilibrio ya que se cancelaría el débito que tiene la entidad A con el Banco de España y simultáneamente, el pasivo generado con el BCE a través del TARGET2; y simétricamente se anula el crédito del Bundesbank con el BCE y de la entidad B al Bundesbank. Los incrementos de 
Sánchez, Paola, Política monetaria del BCE y consecuencias en la Unión Monetaria Europea

pasivo generados fruto de los débitos que mantienen los bancos periféricos se compensan con los activos de los bancos centrales del centro en una situación de normalidad.

Hasta aquí, el comportamiento "normal" que presentaba el sistema TARGET en los años previos a la crisis. Con el mercado interbancario funcionando con normalidad, las entidades repondrían su liquidez acudiendo a otra entidad privada, saldándose las cuentas en el banco central correspondiente. Con el comienzo de la crisis, dos hechos agravan los desequilibrios. El primero de ellos es la negación por parte de los bancos alemanes a refinanciar los préstamos vencidos que concedieron a los bancos españoles. Como los primeros dejan de prestarles a los bancos españoles, acuden al BCE a buscar la liquidez necesaria para seguir operando. El segundo, es la fuga de capitales del año 2011 desde la periferia al centro europeo que intensifica los desequilibrios.

Con la parálisis del mercado interbancario, aunque se sigue realizando la transferencia de depósitos del Banco A al Banco B (por importaciones o retirada de inversión privada), el banco $A$ no puede recuperar sus reservas a través de un préstamo del Banco $B$. Por esto, los activos y pasivos derivados de la operación, persistirán y el Banco A tendrá que acudir al Banco de España para reponer las reservas necesarias recurriendo a operaciones de financiación a corto y largo plazo del Euro-sistema ${ }^{6}$. El Banco de España interviene en último recurso cuando el sistema se paraliza y la banca nacional se queda sin garantías. Ahora lo que ocurre es que las reservas que antes prestaba el Banco $\mathrm{B}$ ahora las presta el BCE, y Alemania presta automáticamente a través del TARGET2, y ya no de forma privada. Esto último ocurre porque el banco privado decide depositar su liquidez sobrante en el BCE ya que le sale más rentable que no prestarla a nadie porque existe una falta de confianza hacia las entidades privadas en las que sí confiaba antes de la crisis.

El debate existente surge cuando es el BCE el que acude a los mercados secundarios a apoyar la liquidez del sistema. ¿Debe el BCE apoyar la financiación de los problemas de liquidez de los países periféricos? El problema de fondo es, por tanto, un problema de política económica en el que se muestra la falta de cohesión existente entre los países europeos. El debate iniciado por Sinn saca a la luz problemas de funcionamiento del sistema y utiliza argumentos que generan, si cabe, un mayor aumento de la desconfianza para justificar así las políticas de austeridad.

\section{PRESENTACIÓN Y ANÁLISIS DE RESULTADOS}

\subsection{Origen de los desequilibrios}

La parálisis del mercado interbancario, marcó un antes y un después en las posiciones deudoras y acreedoras de los distintos países con respecto al BCE.

\footnotetext{
${ }^{6}$ Se trata de operaciones semiautomáticas de financiación como son las operaciones principales de financiación (OPF) y las operaciones que financian a más largo plazo (OFPML) u otras discrecionales.
} 
Sánchez, Paola, Política monetaria del BCE y consecuencias en la Unión Monetaria Europea

La crisis de liquidez experimentada en el sistema financiero a partir del año 2007, hizo que se cortase el suministro de préstamos por parte de los bancos.

Así lo señala lyer et al. (2014):

La crisis comenzó en agosto de 2007 en Europa, cuando el mercado interbancario, una fuente crucial de liquidez para los bancos en Europa, comenzó a experimentar tensiones significativas. Por ejemplo, los diferenciales de los préstamos interbancarios subieron significativamente y el Banco central Europeo (BCE) tuvo que inyectar grandes cantidades de liquidez.

El déficit de liquidez existente se cubre con préstamos de política monetaria, siendo esto lo que se observa en el balance del Banco Central. Un aumento de los billetes en circulación, de las reservas mínimas requeridas o de los saldos en las cuentas corrientes del sector público incrementa el déficit de liquidez y obliga a las entidades de crédito a tomar fondos del Banco Central, por lo que aumentan los préstamos de política monetaria. Como opción alternativa, un aumento de los activos financieros del Banco Central disminuye el déficit de liquidez, lo que reduce los préstamos de política monetaria (Alonso, 2008).

En el caso del Euro-sistema, existen ciertas entidades de contrapartida que son aquellas con las cuales el Euro-sistema efectúa determinadas operaciones de política monetaria. Para ello deben cumplir los criterios generales de selección comunes a toda la zona del euro como son el estar sujetas al sistema de reservas mínimas obligatorias establecido por el Euro-sistema, ser financieramente solventes, y cumplir los requisitos operativos que los bancos centrales nacionales y, en su caso, el BCE establezcan. Estas entidades podrán participar en operaciones de mercado abierto del Euro-sistema y acceder a las facilidades permanentes. Sin embargo, en muchos casos las entidades de crédito por razones operativas derivadas generalmente de su reducido tamaño, prefieren no acceder a esta condición de entidad de contrapartida (Alonso, 2012).

La crisis bancaria se relaciona directamente con los desequilibrios de TARGET2 de la siguiente manera. Las instituciones financieras no monetarias ${ }^{7}$ eran hasta la crisis el principal canal de captación de financiación externa y, aunque las Cuentas Financieras del Banco de España no ofrecen información al respecto, la mayoría de los valores distintos de acciones eran emisiones a largo plazo relacionadas con el mercado hipotecario, bien a través de cédulas hipotecarias o de bonos de titulización. A través de estas instituciones se captó un importe equivalente al $0,4 \%$ del PIB. Con la crisis, esta financiación se redujo, y las instituciones financieras monetarias ${ }^{8}$ también redujeron su

\footnotetext{
7 Son todas aquellas instituciones financieras que se dedican principalmente a la intermediación financiera y no son instituciones financieras monetarias. Está integrado por instituciones financieras que se dedican principalmente a la intermediación financiera, incurriendo en pasivos distintos del efectivo, los depósitos y/o sustitutivos próximos de los depósitos procedentes de unidades institucionales que no sean instituciones financieras monetarias. Por ejemplo: Fondos de Inversión Mobiliaria, Sociedades de Inversión Mobiliaria, Fondos y Sociedades de Inversión Inmobiliaria, Sociedades de valores, fondos de titulización de activos, Sociedades y fondos de capital-riesgo y sociedades emisoras de participaciones preferentes.

${ }^{8}$ Entidades de crédito residentes en la zona -definidas con arreglo al derecho comunitario- y todas las instituciones financieras residentes cuya actividad consiste en recibir depósitos o sustitutos próximos de los depósitos de entidades distintas de las instituciones financieras monetarias y en conceder créditos o
} 
Sánchez, Paola, Política monetaria del BCE y consecuencias en la Unión Monetaria Europea

captación de financiación exterior, con lo que una parte significativa de los recursos financieros externos ahora provienen de las facilidades de liquidez instauradas por el BCE.

Aunque el BCE dispone de operaciones convencionales para proporcionar liquidez al sistema como las facilidades permanentes, las operaciones de mercado abierto (operaciones principales para suministrar liquidez al sistema) y el mecanismo de reservas mínimas, durante la crisis se han empleado otras líneas de financiación menos convencionales.

Para solucionar los problemas de liquidez existentes desde el inicio de la crisis, el BCE desarrolló una línea de financiación para dotar de liquidez al sector financiero denominada LTRO (Long-Term Refinancing Operation), esto es, operaciones de financiación a largo plazo. Estas operaciones consisten en grandes subastas de liquidez llevadas a cabo desde diciembre de 2011 y en momentos puntuales, en operaciones de refinanciación a tres años. Tienen adjudicación plena y a un tipo fijo del uno por ciento.

Básicamente se trata de operaciones mediante las cuales el BCE presta dinero muy barato a la banca privada. Es uno de los negocios más rentables para los bancos durante la crisis dado que el BCE presta al $1 \%$ anual y los bancos pueden prestarlo al 5\%, 7\% 0 10\%, multiplicando sus ganancias y superando los problemas internos.

La primera de estas subastas tuvo lugar el 21 de diciembre de 2011, y en ella el BCE prestó cerca de 490.000 millones de euros a 523 entidades financieras de Europa; en la segunda de ellas, en marzo de 2012, prestó aproximadamente 530.000 millones de euros y participaron más de 800 bancos. La diferencia con respecto a las operaciones de mercado abierto a medio y corto plazo, es la extensión del vencimiento, con lo que se evitan preocupaciones a corto plazo para intentar así que el crédito fluya a través de préstamos a familias y empresas. Sin embargo, lo único que se ha conseguido ha sido apoyar la compra de deuda soberana y la capitalización de los bancos a través del crédito barato.

Además de estas operaciones de financiación a más largo plazo, el BCE anunció otras medidas como la reducción del coeficiente de reserva del $2 \%$ al $1 \%$ y el incremento de la disponibilidad de garantías ${ }^{9}$. Debido a esto, se produce un rápido deterioro de la Posición de Inversión Internacional (PII) de los países de la periferia europea y en concreto, en los activos netos frente al Euro-sistema, que se convierten en la principal fuente de financiación ${ }^{10}$.

\footnotetext{
invertir en valores por cuenta propia -al menos en términos económicos-. Este último grupo está compuesto, fundamentalmente, por fondos del mercado monetario.

${ }^{9}$ De conformidad con el artículo 18.1. de los Estatutos del SEBC, todas las operaciones de crédito del Euro-sistema (es decir, las operaciones de inyección de liquidez) han de basarse en garantías adecuadas. Se distinguen dos categorías: la primera se compone de instrumentos de renta fija negociables que cumplen unos criterios de selección uniformes para toda la zona euro y que especifica el BCE; la segunda incluye otros activos, negociables y no negociables que resultan de especial importancia para los mercados financieros y los sistemas bancarios nacionales, y cuyos criterios de selección los establecen los bancos centrales nacionales, previa aprobación del BCE.

${ }^{10}$ Véase Calvo, A. y Paúl, J. (2008).
} 
Sánchez, Paola, Política monetaria del BCE y consecuencias en la Unión Monetaria Europea

Se han observado cambios en las entidades demandantes de liquidez al Euro-sistema. $\mathrm{Ha}$ disminuido la demanda de entidades que intermediaban en los mercados interbancarios. Las que antes tomaban prestado del banco central (aportando garantías), para posteriormente redistribuir esos fondos entre otras entidades, ganando un pequeño diferencial, prácticamente han cesado en esa actividad, ya que la remuneración que obtenían antes, ahora les resulta insuficiente para hacer frente a los riesgos en que incurren y que se perciben mayores. Asimismo, también ha desaparecido la demanda de las entidades que antes invertían en productos de más largo plazo financiándose semanalmente en el banco central. Por el contrario, han aparecido como demandantes de liquidez del banco central entidades que antes se financiaban en el mercado a largo plazo (esto es, emisores de bonos y titulizaciones), al no encontrar ahora un mercado adecuado para sus emisiones, y aquellas instituciones que han ido incorporando a sus balances los activos que antes estaban en manos de los vehículos de inversión ${ }^{11}$ (Alonso, 2012; 8).

Junto con esto, el BCE bajó los requisitos de los activos admitidos como garantía. El hecho de inyectar liquidez al sistema de esta forma y la relajación de los requisitos para obtener financiación se ha visto reflejado en el aumento de los saldos TARGET2 en el Euro-sistema.

\subsection{La evolución del sistema TARGET2}

A partir del año 2007, el balance del sistema TARGET2 comienza a expandirse de forma considerable. Tal como se observa en el gráfico 2, los países del centro (Alemania, Holanda, Luxemburgo y Finlandia), comenzaron a experimentar posiciones acreedoras frente al Euro-sistema, mientras que los países de la periferia (Grecia, Italia, Irlanda, Portugal y España), intensificaron su posición deudora. Posiciones que aumentan a partir de septiembre de 2011, cuando el BCE intensificó las medidas de apoyo a la liquidez.

Gráfico 2. Balance del TARGET2 (billones de euros).

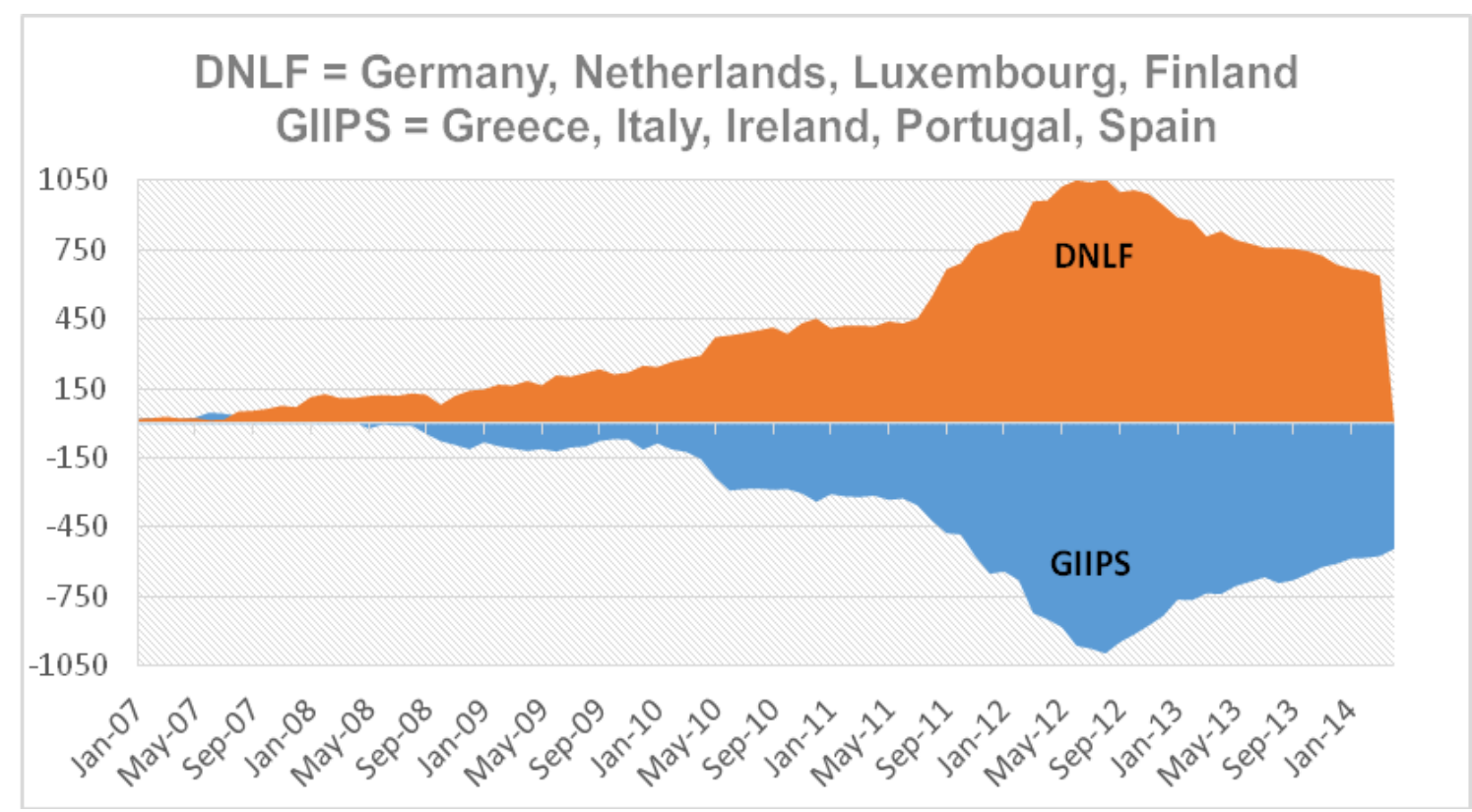

Fuente: Euro Crisis Monitor, Institute of Empirical Economic Research, Osnabrück University.

\footnotetext{
${ }^{11}$ Se refiere a aquellos inversores que se financiaban en el mercado mediante emisiones de títulos a corto plazo (conocidos como asset backed commercial paper o $\mathrm{ABCP}$ ).
} 
Sánchez, Paola, Política monetaria del BCE y consecuencias en la Unión Monetaria Europea

El origen de estos desequilibrios vino dado por la parálisis del mercado interbancario, que ha sido explicada en el punto anterior. El mercado interbancario es una fuente crucial de liquidez para los bancos europeos, y a partir de la crisis empezó a experimentar fuertes tensiones. Para evitar un colapso, el BCE llevó a cabo políticas de reducción del tipo de interés, pero además introdujo medidas temporales no convencionales de "apoyo reforzado al crédito" como complemento a los recortes en los tipos de interés oficiales.

González-Páramo (2012), las sintetiza de la siguiente manera:

- Subastas a tipo de interés fijo.

- Operaciones de financiación adicionales con vencimiento a uno y tres meses, así como la provisión de financiación a vencimientos más largos, de hasta 3 años a partir de diciembre de 2011.

- Ampliación del sistema de activos de garantía ${ }^{12}$. En diciembre de 2011, el BCE anunció que ampliaría la lista de activos de garantía para aumentar la disponibilidad de valores respaldados por préstamos a la economía real.

- Programas de adquisiciones directas de bonos garantizados en 2009 y 2011.

- Introducción de operaciones de inyección de liquidez en moneda extranjera.

- Fomento de la actividad de los mercados monetarios tales como la reducción del coeficiente de reserva y la suspensión de operaciones de ajuste que se llevan a cabo al final de los periodos de mantenimiento.

- Un programa de adquisiciones directas de instrumentos de renta fija.

Estas medidas de intermediación estuvieron acompañadas por un aumento del tamaño del balance, que llegó a alcanzar el $20 \%$ del PIB. Lo que ha hecho el BCE puede ser considerado el equivalente a una actuación como "prestamista de última instancia"13. En vista de la parálisis del mercado monetario interbancario, el BCE ofreció una "intermediación de última instancia". La flexibilidad del sistema de garantías permitió facilitar el acceso de la banca a las operaciones de liquidez, y brindarle un apoyo indirecto a los mercados de activos que sufrieron tensiones de liquidez durante la crisis.

A diferencia de lo que ocurría antes de la crisis cuando los bancos obtenían la liquidez en el mercado interbancario, ahora recurren a la financiación del BCE, generando un pasivo frente al Euro-sistema. Lo que ocurre ahora es que los bancos centrales de la periferia intervienen, y las reservas que antes eran prestadas por un banco privado, ahora las presta el BCE a través del sistema TARGET2 con los bancos centrales nacionales como intermediarios.

La afirmación de Werner Sinn (2012), por su parte, muestra la idea de que los desequilibrios originados en el sistema TARGET2 son consecuencia de los desequilibrios en las cuentas corrientes de los países de la zona euro.

\footnotetext{
12 Se reduce el umbral mínimo para determinados valores respaldados por activos, y se aceptan como garantía otros créditos no fallidos (préstamos bancarios).

13 Esta política generó numerosas críticas procedentes principalmente de Alemania, ya que argumentaban que incumplía el artículo 123 del Tratado de Lisboa (artículo 104 del tratado de Maastrich) el cual prohíbe al BCE la financiación a los Estados miembros de la Unión Europea. En todo caso, esta financiación se ha dirigido a la banca privada, y solamente ha comprado deuda de forma ocasional en el mercado secundario, nunca en el mercado primario de deuda.
} 
Sánchez, Paola, Política monetaria del BCE y consecuencias en la Unión Monetaria Europea

Así aquellos países con grandes déficits corrientes (periferia europea) reflejarán posiciones deudoras en el TARGET2, mientras que aquellos con grandes superávits, reflejarán posiciones acreedoras. Además, como recomendaciones económicas para solucionar esta problemática se sugieren dos rutas: políticas de austeridad y reformas estructurales. Las primeras abarcan a la política fiscal y monetaria restrictiva (caída de los salarios y aumento de las tasas de interés para favorecer la entrada de capital extranjero $\left.{ }^{14}\right)$; y la segunda, en establecer políticas dirigidas a aumentar el grado de competitividad en el mercado de bienes y en la regulación del empleo, aumentando por tanto, el grado de flexibilidad laboral.

Gráfico 3. Saldo por cuenta corriente de Alemania, Irlanda, Grecia, España, Italia y Portugal durante la crisis (miles de millones de euros).

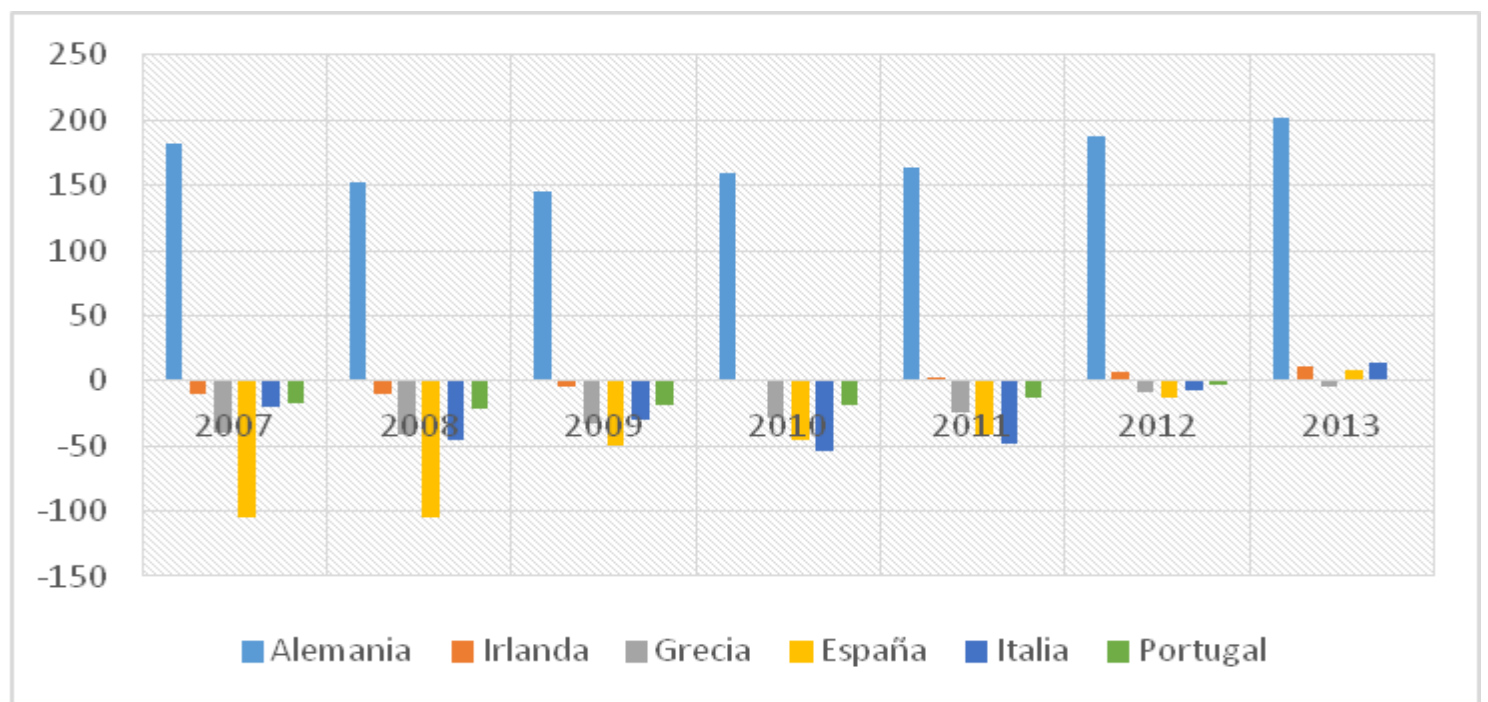

Fuente: AMECO. http://ec.europa.eu/economy finance/ameco/user/serie/ResultSerie.cfm

Gráfico 4. Balanzas del TARGET2 por países (miles de millones de €).

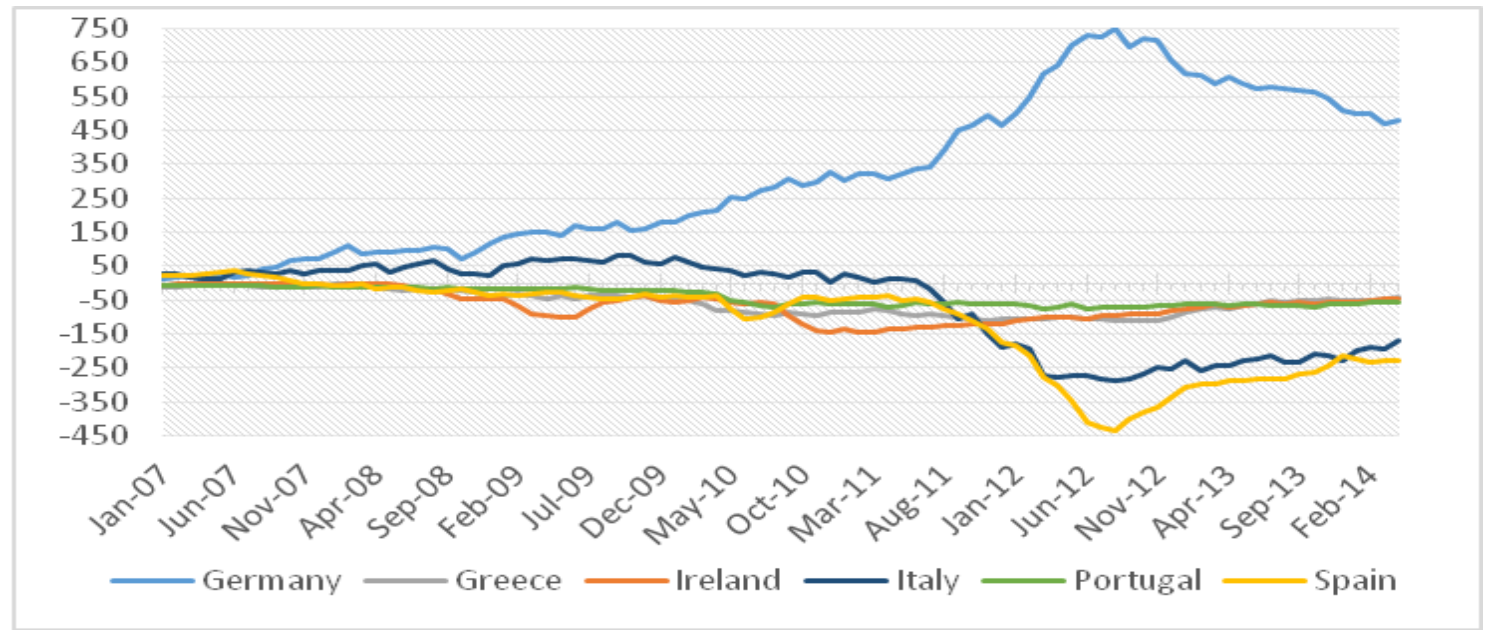

Fuente: Euro Crisis Monitor, Institute of Empirical Economic Research, Osnabrück University.

\footnotetext{
${ }^{14}$ Esta política acabó profundizando la recesión y no una entrada de capital.
} 
Sánchez, Paola, Política monetaria del BCE y consecuencias en la Unión Monetaria Europea

Analizamos a continuación las debilidades que muestra la argumentación de Sinn:

a. En primer lugar, si observamos los saldos de las cuentas corrientes de los países con mayores posiciones deudoras en el Euro-sistema (gráfico 3), se muestra claramente la posición superavitaria de Alemania de 2007 a 2013 y deficitaria del resto de países en el mismo periodo exceptuando a Irlanda desde 2010, cuando ya experimenta superávit. Relacionando los resultados de las cuentas corrientes de los países con sus posiciones en el sistema TARGET (gráfico 4), no se muestra correlación alguna entre los déficits por cuenta corriente que presentan los países y sus posiciones deudoras en el sistema. Por el contrario, lo que se muestra al observar ambas gráficas es que los déficits por cuenta corriente de los países son mayores durante los primeros años analizados, cuando su posición deudora frente al Euro-sistema era menor. En cambio, estos déficit van disminuyendo y las posiciones deudoras son cada vez mayores. Por tanto, gráficamente podemos observar que no existe relación entre el déficit/superávit por cuenta corriente que presente un país con la posición que este país presente frente al Eurosistema dentro del sistema TARGET.

b. En segundo lugar, se puede llegar a pensar que la argumentación de Sinn muestra la intención de justificar las medidas de austeridad y las políticas dirigidas a aumentar el grado de competitividad ya que su argumentación señala a los déficits corrientes de los países del sur como los causantes de los desequilibrios en el sistema TARGET2. Su receta para solucionar el problema sería que los países aplicasen las medidas de austeridad necesarias para reducir sus déficits corrientes y aumentar su competitividad. Sin embargo, para que un país presente superávit por cuenta corriente es necesario que exista un país con una posición contraria en su balanza de pagos. En el caso europeo, Alemania será el país que debería reducir su superávit para que los países periféricos redujeran su déficit por cuenta corriente.

c. En tercer lugar, hay que señalar que la comparación de ambas variables no es coherente, ya que mientras la balanza por cuenta corriente recoge variables flujo (en un período) los saldos TARGET son variables stock, por tanto, para ver si existe o no correlación, habría que ver los movimientos en el TARGET durante el período, y no los saldos acumulados. Por otro lado, la balanza por cuenta corriente no muestra solamente las operaciones con la Unión Europea, sino que se recogen las operaciones de cada país con el resto del mundo; mientras que el sistema TARGET solo recoge los pagos entre las distintas instituciones de la Unión Monetaria Europea.

Una vez señalados los problemas que presenta la argumentación de Sinn, pasamos a analizar detenidamente la posición de De Grauwe. Este autor, argumenta que los balances del TARGET2 son fruto del miedo y el pánico que afecta a los mercados de bonos soberanos, donde los tenedores de bonos venden aquellos bonos de países en los que desconfían y compran los de los países considerados seguros. Además, su modelo econométrico muestra correlación entre la prima de riesgo de los países y las posiciones deudoras (a mayor prima de riesgo, mayor es su posición deudora frente al Euro-sistema). Se entiende entonces que la salida de capital de los países menos seguros aumenta y que como contrapartida se observa un incremento de las posiciones 
Sánchez, Paola, Política monetaria del BCE y consecuencias en la Unión Monetaria Europea

deudoras de estos países en el sistema TARGET2. Esto ocurre porque la salida de capital se tiene que ver compensada con un aumento del endeudamiento externo.

Gráfico 5. Cantidad de crédito concedida por el BCE a cada uno de los países periféricos y su posición frente al Euro-sistema.
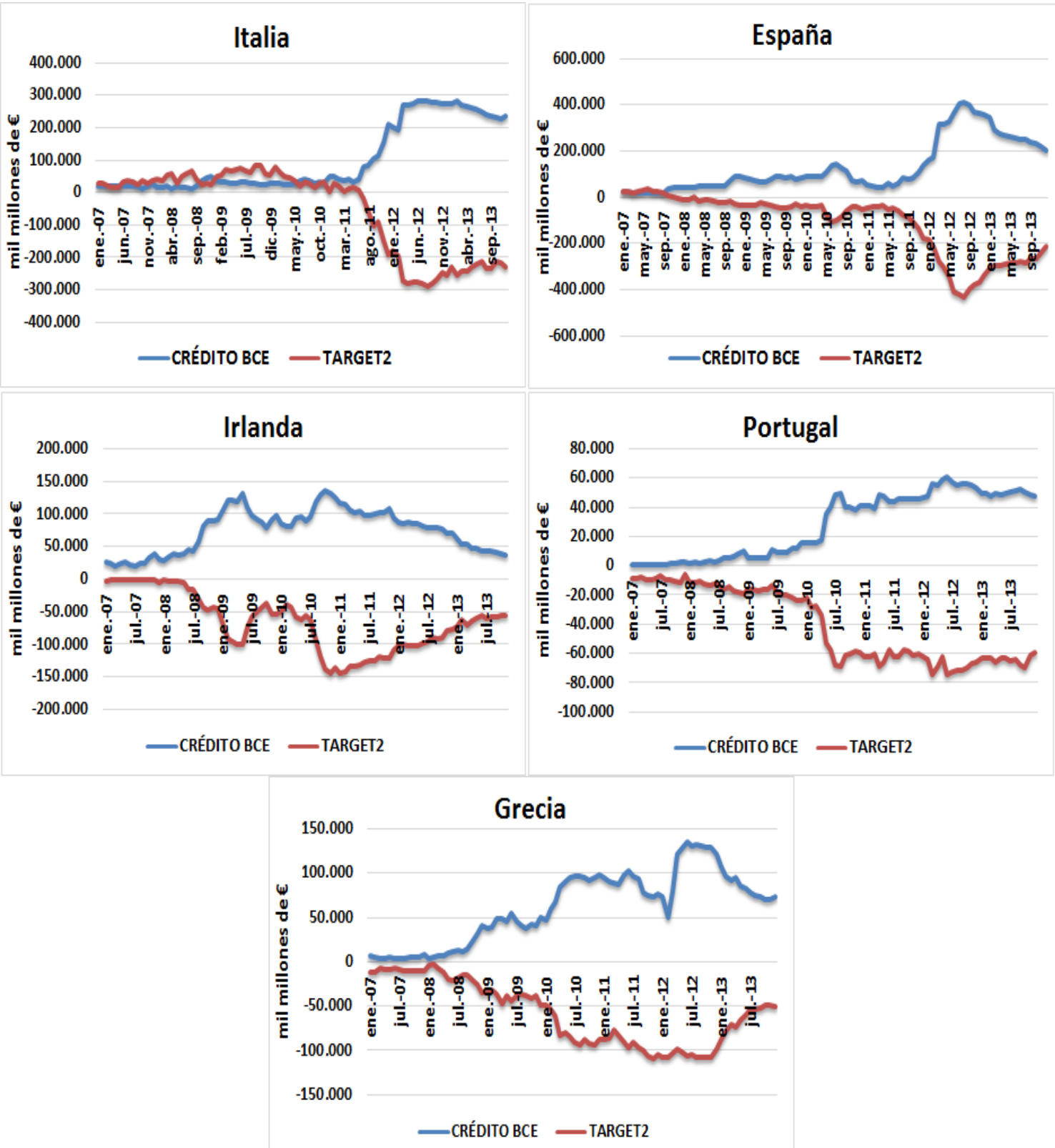

Fuente: elaboración propia a partir de datos de Euro Crisis Monitor.

En el gráfico 5, se muestran las posiciones deudoras de los países periféricos frente al Euro-sistema junto a la cantidad de crédito concedida por parte del BCE a estos países. Se observa, salvo en momentos puntuales, una clara correlación que explica que los desequilibrios se dan a partir del aumento de la financiación concedida por parte del BCE a las entidades financieras de los países periféricos para cubrir la falta de liquidez. 
Sánchez, Paola, Política monetaria del BCE y consecuencias en la Unión Monetaria Europea

Lo que ocurre en el trabajo de De Grauwe (2012) es que el autor no analiza por qué esta salida de capital conlleva un incremento de las posiciones deudoras en el sistema TARGET2. Esto ocurre porque la parálisis del mercado interbancario va a hacer que estos países acudan al BCE en busca de crédito, ya que la financiación que antes recibían a través de otras instituciones financieras ha disminuido considerablemente debido a la desconfianza existente en los mercados. Esto se va a reflejar en el aumento de los préstamos concedidos por el BCE y consecuentemente provocará un incremento del endeudamiento de los países.

Por tanto, bajo este análisis se puede afirmar que la hipótesis de Sinn sobre el origen de los desequilibrios es falsa, ya que la posición en el sistema TARGET2 no viene dada como consecuencia de la falta de competitividad de los países periféricos y la necesidad de financiar los déficits por cuenta corriente de estos países; sino que esta posición es consecuencia de la política llevada a cabo por el BCE (como analizaremos en el siguiente punto) que ha consistido en inyectar grandes cantidades de dinero a las entidades financieras del sur de Europa para compensar la falta de liquidez consecuencia de la parálisis del mercado interbancario.

\subsection{La intervención del BCE y la reducción de desequilibrios}

Las decisiones políticas son determinantes a la hora de analizar la evolución de los desequilibrios en el TARGET2. Los mercados financieros acusaron a las instituciones europeas de no ser capaces de mantener la cohesión y de no saber decidir una política económica eficaz. Tanto en Italia como en España, el aumento de los pasivos acumulados en el TARGET2 se hizo más evidente en julio de 2011. En agosto de 2012 los pasivos de TARGET2 alcanzaron valores máximos de 289,2 mil millones de euros en el caso italiano y 434,4 mil millones de euros en el caso español. Ambos fueron los países que alcanzaron las posiciones deudoras más grandes en el Euro-sistema. A partir de agosto de 2012, los pasivos acumulados disminuyen en ambos países.

En el gráfico 6, se observan los momentos clave en la evolución de los desequilibrios en el TARGET2, entre los que se destacan tres: julio de 2011, febrero-marzo 2012 y julio-septiembre 2012. Cada uno de ellos representa un bloque de decisiones políticas y económicas que las instituciones europeas diseñaron para hacer frente a la crisis de deuda soberana. Si tenemos esto en cuenta, se puede afirmar que los factores determinantes de los desequilibrios TARGET2 se atribuyen más a decisiones de política económica que a indicadores macroeconómicos de los países como puede ser el saldo por cuenta corriente o la posición financiera internacional, así como la falta de competitividad de los países de la periferia. 
Sánchez, Paola, Política monetaria del BCE y consecuencias en la Unión Monetaria Europea

Gráfico 6. Decisiones de política económica tomadas durante la crisis, situadas sobre el balance del TARGET2.

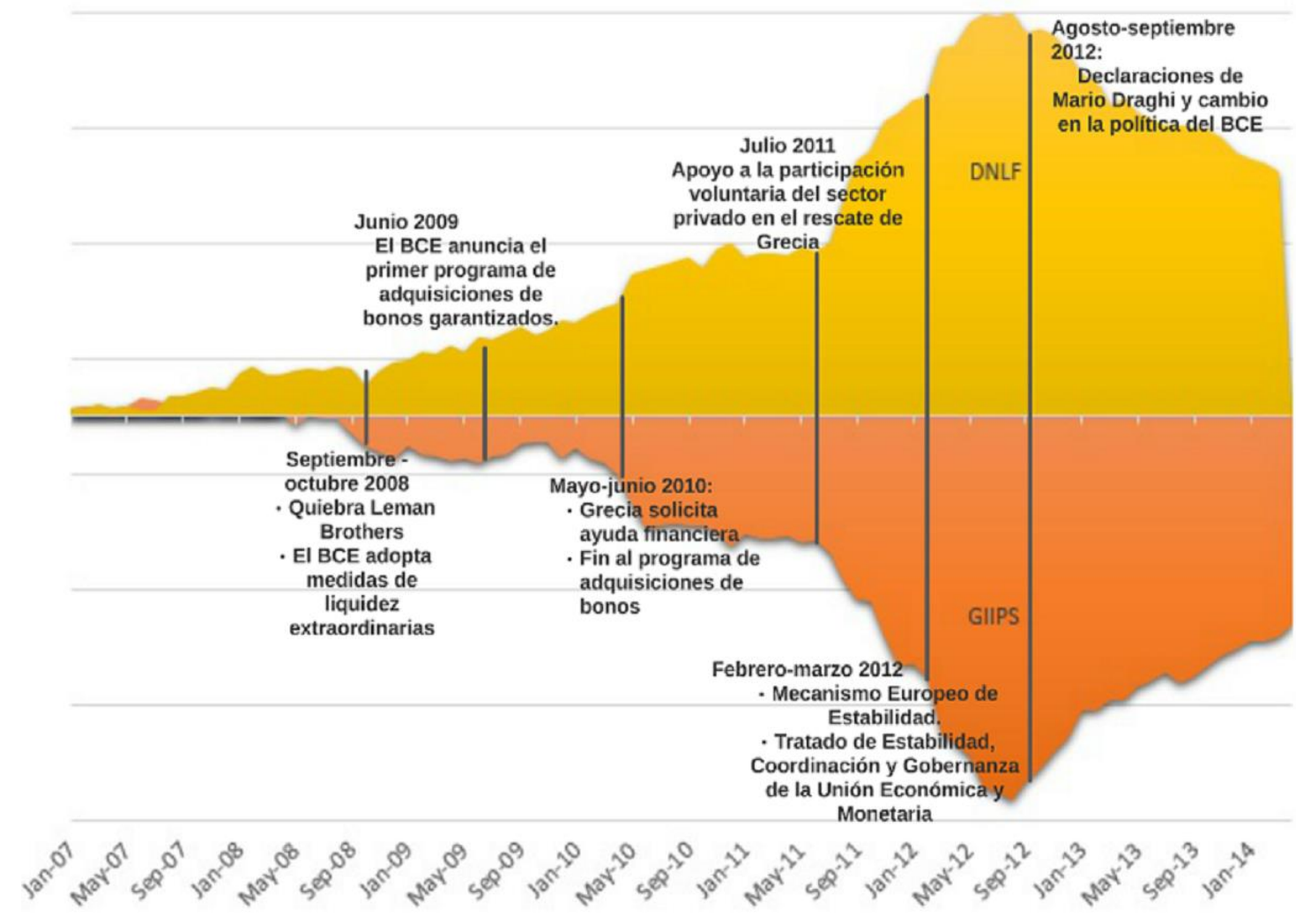

Fuente: elaboración propia a partir de datos del BCE y Euro Crisis Monitor.

El 21 de julio de 2011, los Jefes de Estado y de Gobierno de la Zona Euro expresaron su apoyo a la participación voluntaria del sector privado, y en particular a entidades de crédito en el programa de ajuste económico y financiero para Grecia. El entonces presidente, Jean Claude Trichet, advirtió sobre las posibles consecuencias de un impago de Grecia, y esto impulsó la inestabilidad de los mercados financieros. Además, las tensiones en el mercado de bonos y el mercado interbancario disminuyó la eficacia de los mecanismos de transmisión de la política monetaria, y la reducción del crédito a familias y empresas. No fue hasta febrero de 2012 cuando esta participación voluntaria del sector privado tomó forma en un acuerdo, que a pesar de su carácter "voluntario", implicaba una quiebra parcial de Grecia y la renuncia del gobierno griego a su soberanía nacional.

Junto con las decisiones tomadas por el BCE para tratar de resolver la situación griega, desde el año 2011 se fueron sucediendo una serie de reformas que tenían como objetivo calmar a los mercados, creyendo así que la situación económica europea mejoraría.

a. El primer elemento del proceso de reformas fue puesto en marcha en noviembre de 2011, y estaba formado por un conjunto de reglamentos relativos a los procedimientos y sanciones a seguir en caso de desequilibrios macroeconómicos. Sin embargo, tras este proceso, las tensiones en los mercados financieros se acentúan y el deterioro se observa en la evolución de los saldos TARGET2. Los mercados no consideraron suficientes estas medidas (Astarita y Purificato, 2013). 
Sánchez, Paola, Política monetaria del BCE y consecuencias en la Unión Monetaria Europea

b. El segundo elemento lo representa el tratado que constituye el Mecanismo Europeo de Estabilidad, firmado en febrero de 2012 por los estados miembros de la Zona Euro. Su tarea es gestionar los programas de ayuda financiera a los países de la zona euro. Así, se convierte en un mecanismo permanente de resolución de crisis para los estados.

c. El tercer elemento lo forma el "Tratado de Estabilidad, Coordinación y Gobernanza de la Unión Económica y Monetaria" firmado en marzo de 2012 por los Jefes de Estado y de Gobierno de todos los estados de la Unión Europea. El tratado establece entre otras cosas que: a) el déficit presupuestario estructural de la administración pública, ajustado por el ciclo económico, no debe superar el $0,5 \%$ del PIB a precios de mercado, con la obligación de incorporar esta norma presupuestaria en la legislación nacional; b) las partes contratantes deben reducir una vigésima parte al año el ratio Deuda-PIB cuando se supere el $60 \%$.

El día 30 de ese mismo mes, el Eurogrupo decidió destinar 700 miles de millones de euros al Mecanismo Europeo de Estabilidad, y al plan Europeo para facilitar la Estabilidad Financiera. Esta decisión puede ser considerada como el paso final en el proceso de reforma lanzado desde las instituciones europeas para prevenir y manejar las situaciones de inestabilidad financiera de los estados de la UME.

A pesar de los esfuerzos por conseguir la estabilidad financiera, estas medidas no fueron suficientes para calmar los mercados. Por este motivo, el presidente del BCE Mario Draghi, en agosto de 2012 hizo referencia a un nuevo programa para la compra de bonos soberanos, que reemplazará el programa del Mercado de Valores (SMP) ${ }^{15}$, en vigor desde mayo de 2010. Días antes, Draghi afirmó: "dentro de nuestro mandato, el BCE está dispuesto a hacer lo que sea necesario para preservar el euro" 16 .

En septiembre de 2012 se explicó el programa a aplicar, diseñado con el fin de eliminar las tensiones existentes en el mercado de bonos soberanos. Se creaba así la posibilidad por parte del BCE de comprar bonos de manera ilimitada. Para ello, los países debían acogerse a un programa de ajuste macroeconómico y haber cumplido las condiciones establecidas en estos programas. Además, el BCE se reservaba el derecho de activar, continuar o interrumpir el programa para un país concreto; además de esterilizar la liquidez.

Fue a partir de las declaraciones realizadas por Mario Draghi en el año 2012, cuando las tensiones en los mercados financieros disminuyeron, y a su vez se observa una reducción clara en la cantidad de créditos concedidos por el BCE

\footnotetext{
15 Programa destinado a hacer frente a las tensiones en determinados segmentos del mercado que obstaculizaban el mecanismo de transmisión de la política monetaria. Este mecanismo es el proceso que el BCE emplea con el objetivo de influir en los precios de la zona del euro a través de sus tipos de interés. En el marco del SMP, si este mecanismo se ve obstaculizado por segmentos disfuncionales del mercado y la señal de los tipos de interés no llega por igual a todos los participantes de la zona del euro, el BCE podría intervenir comprando en el mercado secundario (es decir, a las entidades de crédito y a precios de mercado) los valores que normalmente acepta como activos de garantía. Las últimas adquisiciones en el marco del SMP se realizaron en febrero de 2012 y el programa se dio por concluido en septiembre de 2012.

${ }^{16}$ Discurso en Londres, 26/07/2012.
} 
Sánchez, Paola, Política monetaria del BCE y consecuencias en la Unión Monetaria Europea

a los países de la periferia europea. En consecuencia, los desequilibrios en el sistema TARGET2 se van corrigiendo, y disminuyen de forma considerable en todos los países que previamente presentaban posiciones deudoras.

\section{CONCLUSIONES}

Tras el inicio de la crisis financiera del año 2007, se desencadenaron una serie de problemas tanto políticos como económicos que dieron lugar a la mayor crisis que ha sufrido el euro desde su puesta en circulación en el año 2001. Además, se generaron debates entre economistas de distintos países y surgieron fracturas político-sociales dentro de la propia Unión Europea.

El debate iniciado por Sinn en el año 2011 cuando irrumpió la crisis de deuda, cuestionaba el funcionamiento del sistema de pagos. La intensificación de los desequilibrios en el sistema TARGET2 sirvió de argumento para autores ortodoxos como Sinn en favor de las medidas de austeridad aplicadas en los países de la periferia y para justificar también la necesidad de que los países del sur de Europa establecieran programas de política económica que mejoraran su competitividad.

Las hipótesis principales de este trabajo plantean por un lado, que los desequilibrios surgidos tras la crisis financiera no se deben a una financiación del Banco Central Europeo de los déficits por cuenta corriente de los países de la periferia; y por otro lado, que la forma en la que inicialmente se plantea el debate muestra una orientación clara de política económica en favor de las políticas de austeridad.

En primer lugar, la situación de falta de liquidez que afectaba a muchas entidades privadas de la periferia europea hizo que el BCE se decidiera a intervenir inyectando liquidez al sistema por medio de políticas no convencionales. Se destinó una gran cantidad de liquidez a las entidades que presentaban problemas de financiación, y fue dirigida en su mayoría a entidades privadas de países del sur de Europa, más concretamente a España e Italia. De ahí que el sistema TARGET2 muestre las mayores posiciones deudoras para estos países.

En segundo lugar, no se encuentra una correlación clara entre los desequilibrios en el sistema TARGET2 y las balanzas de pagos de los países periféricos. En contra de lo que señala Sinn, las posiciones deudoras del Eurosistema se hacen mayores en los momentos en los que los déficits por cuenta corriente de los países periféricos son menores, o que incluso presentan saldos positivos.

A favor de De Grauwe hay que decir que es cierto que la salida de capital en los primeros años de la crisis generó un aumento del endeudamiento de los países con mayores posiciones deudoras en el sistema TARGET2. La falta de confianza implicó un problema de liquidez importante en las entidades financieras de muchos países del sur de Europa que no pudo ser compensada con préstamos del mercado interbancario a partir del año 2011, y dio lugar a 
Sánchez, Paola, Política monetaria del BCE y consecuencias en la Unión Monetaria Europea

que se intensificaran las posiciones deudoras de ciertos países frente al Eurosistema.

Por otro lado, el sistema TARGET2 es un sistema contable donde se reflejan los pagos entre las distintas entidades financieras de los países miembros, lo cual quiere decir que los desequilibrios de su balance no son consecuencia de su mal o buen funcionamiento, sino que los desequilibrios que se muestran son el reflejo de otros problemas como la pérdida de confianza de los inversores en los países del sur de Europa y la parálisis del mercado interbancario; y de las decisiones políticas tomadas durante la crisis.

El debate planteado por Sinn no es más que un debate que desvía el punto de mira hacia un problema que no lo es por sí mismo, sino que es el reflejo de otros problemas que afectan a la UEM y que no han sido solucionados. A pesar de que las medidas aplicadas por el BCE a partir del año 2012 han reducido los desequilibrios de forma considerable, esto no quiere decir que se haya solucionado la crisis, ya que, entre otros motivos, la liquidez que se ha inyectado en el sistema ha sido utilizada por las entidades financieras para comprar deuda a un tipo de interés mayor al que les presta el BCE y es por ello que no se han visto los efectos de estas políticas en la economía real.

Por tanto, las medidas que ha llevado a cabo el BCE para intentar solucionar la crisis de deuda, no son más que soluciones superficiales para "calmar los mercados" y restaurar la confianza en la Unión Europea. Esto ha funcionado para reducir los desequilibrios del TARGET2, pero no para solucionar los desequilibrios aún existentes socialmente entre el sur y el centro europeo así como la crisis política que afecta actualmente a la Unión Europea.

EI BCE debería tener en cuenta otras cuestiones a la hora de gestionar la política económica de la UEM, tomando como referencia otros aspectos distintos a un sistema contable o a variables como la prima de riesgo de un país. Los resultados del sistema TARGET reflejan que el diseño de la UEM profundiza las asimetrías existentes entre los países, que se han puesto en evidencia a raíz de la crisis de 2007. Para eliminar los desequilibrios no es suficiente con inyectar más o menos liquidez al sistema, puesto que estas soluciones son temporales; es necesario de rediseñar por completo el sistema permitiendo una transición que elimine las asimetrías y crear un consenso para llegar a una Unión Política. Para ello, muchos países y grupos de poder deberían renunciar a sus privilegios, algo que es muy difícil de conseguir a día de hoy. Por tanto, se trata de un problema político que se solucionará cuando dejen de primar los intereses de unos pocos (países e instituciones privadas) por encima de los de la mayoría. 
Sánchez, Paola, Política monetaria del BCE y consecuencias en la Unión Monetaria Europea

\section{BIBLIOGRAFÍA}

Alonso, J. (2011): "Los déficits estructurales de liquidez y las tensiones en los mercados monetarios" en Estabilidad Financiera, no. 14, Banco de España.

Alonso, J., Conesa, C. (2011): TARGET2: qué significa y qué implica.

Álvarez, I. et ál. (2013): Fracturas y crisis en Europa, ed. Clave Intelectual.

Angelini, P., Nobili, A. y Picillo, M. C. (2009): "The interbank market after August 2007: what has changed and why?" en Banca d'Italia Working Papers, no. 731.

Astarita, C., Purificato, F. (2013): "TARGET2 imbalances and the need for a lender of last resort" en MPRA Paper, no. 51124, noviembre, Universidad de Nápoles.

Calvo, A. y Paúl, J. (): "Efectos de la crisis financiera internacional sobre la financiación de la economía española" en Clm. Economía, no. 14, pp. 55-80.

Cecioni, M., Ferrero, G. (2012): "Determinants of TARGET2 imbalances" en Questioni di Economia e Finanza, Banca d'Italia, no. 136.

Cesaratto, S. (2012): "La crisis sin fin de la eurozona: una visión clásicakaleckiana" en Papeles de relaciones ecosociales y cambio global, no. 120, pp.69-88.

Cesaratto, S. (2013): "The implications of TARGET2 in the European balance of payments crisis and beyond", en European Journal of Economics and Economic Policies: Intervention, vol. 10, no. 3, pp.359-382.

Combis, X. (2013): "El mercado interbancario en tiempos de crisis: ¿las cámaras de compensación son la solución?", en Observatorio de Divulgación Financiera, no. 12, noviembre.

Costas, A., Lago-Peñas, S. (2013): "The debt crisis, the Euro and the European political integration: reflections from the economy", en MPRA Paper, no. 45563, 27 de marzo.

De Grauwe, P., Ji, Y. (2012): "What Germany should fear most is its own fear: An analysis of TARGET2 and current account imbalances", en CEPS Working Document, no. 368, septiembre.

De Grauwe, P., (1993): Teoría de la integración monetaria, Ed. Celeste, Madrid.

Díez, J. R. (2013): “¿Se ha reducido la fragmentación financiera en la zona euro?", en Anuario del Euro 2013, Fundación ICO, pp. 111-131.

European Central Bank (2013): "Target Balances and monetary policy operations", mayo.

European Central Bank (2011): "TARGET2 balances of national central banks in the Euro area". Monthly, Bulletin, October.

European Central Bank (2010): "The payment system-payments, securities and derivatives, and the role of the Eurosystem", Frankfurt.

Eichengreen, Barry (2010): "The Breakup of the Euro Area" in Europe and the Euro, edited by Alberto Alesina and Franceso Giavazzi, University of Chicago Press.

Febrero, E., Uxó, J. (2013): “Understanding TARGET2 imbalances from an endogenous money view", presentado en el Congreso Internacional Crítica de la Teoría Económica y políticas alternativas frente a la crisis global, Universidad Autónoma de México. 
Sánchez, Paola, Política monetaria del BCE y consecuencias en la Unión Monetaria Europea

Godley, W. and Lavoie, M. (2007): Monetary Economics: An Integrated Approach to Credit, Money, Income, Production and Wealth, Basingstoke, Palgrave, Macmillan.

Godley, W. and Lavoie, M. (2012): La economía monetaria. Una revolución contra la teoría económica superficial con el rigor de los modelos de stock-flujo, Ed. Marcial Pons, Madrid.

González-Páramo, J. M. (2012): "La gestión del Banco Central Europeo ante la crisis" en Revista de Economía Mundial, no. 30, pp. 83-102.

lyer, R. et ál. (2014): "Interbank liquidity crunch and the firm credit crunch: evidence from the 2007-2009 crisis", en The Review of Financial Studies, vol. 27, no. 1, pp. 347- 372.

Lubik, T., Rhodes, K (2012): "TARGET2: Symptom, not cause, of Eurozone woes", en Economic Brief, The Federal Reserve Bank of Richmond.

Panico, C., Purificato, F. (2013): "The debt crisis and the European Central Bank's Role of Lender of Last Resort", en Political Economy Research Institute, no. 306, University of Massachusetts Amherst.

Semieniuk, G., van Treeck, T., y Truger, A. (2011): "Reducing economic imbalances in the euro area: some remarks on the current stability programs", 2011-14, no. 694, Working paper, Levy Ecomics Institute.

Sinn, W. (2012): "TARGET losses in case of a euro breakup", Vox EU.

(2012a). "Fed versus ECB: How Target Debts Can Be Repaid", Vox EU, Marzo 10.

(2011): "The ECB's stealth bailout", Vox EU.

Sinn, W. y Wollmershäuser, T. (2012): "Target loans, current account balances and capital flows: the ECB's rescue facility" en Int. Tax Public Finance, 19 , pp. $468-508$.

Steinberg, F., Molina, I. (2012): "El Nuevo gobierno del euro: ideas alemanas, intereses divergentes e instituciones comunes", en Revista de Economía Mundial, no. 30, pp. 59-81.

Uxó, J, Bermejo, F. (2012): "El funcionamiento del sistema TARGET2 desde la Gran Recesión. Una aproximación desde la óptica del circuito monetario" en XIII Jornadas de Economía Crítica, pp. 1103-1137, Sevilla.

Westermann, F. (2012): "Two types of capital flight: Will a common deposit insurance help to stabilise the TARGET2 imbalances?" en Banking Union for Europe: Risks and Challenges, VOX, pp. 57-64.

Westerrmann, F. (2014): "TARGET2 and Central Bank Balance Sheets", Institute of empirical Economic Research, Osnabrück University, Working Paper no. 99, febrero.

Whelan, K. (2013): "TARGET2 and Central Bank Balance Sheets", en el 57th Panel Meeting of Economic Policy, University College Dublin, marzo, 2013. 